\title{
An Empirical Study of Strategic Positioning and Production Efficiency
}

\author{
Hsihui Chang, ${ }^{1}$ Guy D. Fernando, ${ }^{2}$ and Arindam Tripathy ${ }^{3}$ \\ ${ }^{1}$ LeBow College of Business, Drexel University, Philadelphia, PA 19104, USA \\ ${ }^{2}$ College of Business, State of University of New York, Albany, NY 12222, USA \\ ${ }^{3}$ Milgard School of Business, University of Washington-Tacoma, Tacoma, WA 98402, USA
}

Correspondence should be addressed to Guy D. Fernando; gfernando@albany.edu

Received 11 September 2014; Accepted 24 March 2015

Academic Editor: Ching-Jong Liao

Copyright (C) 2015 Hsihui Chang et al. This is an open access article distributed under the Creative Commons Attribution License, which permits unrestricted use, distribution, and reproduction in any medium, provided the original work is properly cited.

\begin{abstract}
We examine the relationship between strategic positioning of firms and their production efficiency. Firms with competitive advantages based on either cost leadership or differentiation are able to outperform their competitors. Firms pursuing a cost leadership strategy seek to be the lowest cost producer, primarily by minimizing inputs for a given level of output, thus concentrating on increasing the efficiency of their production processes. On the other hand, firms that pursue a differentiation strategy rely on innovation, brand development, marketing, and so forth to achieve competitive advantages; therefore such firms do not place high emphasis on production efficiency. Thus the importance of production efficiency for the success of a firm depends on the strategic positioning of the firm. We apply DEA to an archival data for a large sample of publicly listed firms to investigate the importance of production efficiency for firms based on their strategic positioning. We provide empirical evidence that firms pursuing a cost leadership strategy attribute higher importance to production efficiency, while firms pursuing differentiation strategy attribute less importance to production efficiency.
\end{abstract}

\section{Introduction}

Porter [1] posits that firms with competitive advantages based on either cost leadership or differentiation are able to outperform their competitors; in the same vein subsequent studies document that a firm successfully pursuing either a differentiation or a cost leadership strategy is in a better position to achieve superior contemporaneous performance [2, $3]$. While cost leadership is achieved primarily through operational improvements and efficiency, differentiation strategy is built on product innovation or services that are perceived to be different from competitors. However, the success of any firm eventually depends on how well it implements its chosen business strategy [4]. This paper examines firm strategy and its implementation through a novel application of data envelopment analysis (DEA). We use archival data for a large sample of listed firms to empirically investigate the importance of production efficiency for firms based on their strategic positioning. We provide evidence that firms pursuing a cost leadership strategy attribute higher importance to production efficiency, while firms pursuing differentiation strategy attribute less importance to it.

Calthrop, Vice President of Bain International, writes that "Cost leadership is about cost per unit of input, not lowest cost per se" [5]. Thus, firms that pursue a cost leadership strategy are expected to be associated with higher production efficiency. On the other hand, firms that pursue a differentiation strategy rely on innovation, brand development, marketing, and so forth to achieve competitive advantage. Hence, such firms are not expected to place high emphasis on production efficiency. However, to the best of our knowledge, there has not been a formal investigation of this question in a rigorous academic setting. This study aims to overcome this gap in research by using DEA to determine firm production efficiency. Analyzing publicly available data from the Compustat database, our empirical results show that firms which follow a cost leadership (differentiation) strategy are associated with higher (lower) production efficiency. From a practical perspective, this provides both a means of operationalizing, as well as ex-post measuring, and the success of implementation 
of predetermined business strategies of a firm. A necessary prerequisite for firms that want to adopt a cost leadership strategy will be to work on improving production efficiency. It can also be used to measure the success of a cost leadership strategy adoption by evaluating the cost leader's production efficiency compared to the production efficiency of its peers and also the production efficiency frontier of its industry. DEA is ideally suited for this exercise since it aids in the derivation of the industry production efficiency frontier and in the comparison of production efficiencies across firms.

Our study highlights a crucial dichotomy in the differential importance of production efficiency to firms pursuing different business strategies. Production efficiency enhancements help reduce costs and achieve cost leadership in a market; hence production efficiency is very important to cost leaders. Hence, business managers who are looking to enhance production efficiency should first evaluate their business strategy, to ensure that such enhancements will yield the maximum effect. Finally, this study shows the versatility in the application of DEA in its ability to answer research questions in diverse areas of business.

The rest of the paper is organized as follows. In the next section we provide the background literature to motivate our hypotheses. In Section 3, we discuss the empirical estimation including the description of the DEA model and the construction of the strategy measures. Section 4 presents and discusses the empirical results and Section 5 concludes the paper.

\section{Literature Review and Hypotheses Development}

Fried et al. [6] state that "by the efficiency of a producer, we have in mind a comparison between observed and optimal values of its output and input" (page 7). Production efficiency is similarly defined by Coelli et al. [7]. The firm that is able to produce a unit with the minimum amount of inputs will enjoy a competitive advantage that it can leverage to enjoy superior profits or drive competitors from the market. Moreover, Färe et al. [8] posit that "Production efficiency is an important characteristic of producer performance." Thus, higher production efficiency would imply better control and use of a firm's resources.

A firm needs to possess competitive advantages over its competitors in order to outperform them. Porter [1] presents a framework describing two strategies that a firm can use to achieve competitive advantage: cost leadership and differentiation. He also discusses the structure, processes, and the practices that are likely to be identifiable with firms that have a specific strategic orientation. Based on Porter's framework, a firm that chooses and successfully implements a strategy, based on either cost leadership or differentiation, will be in a position to effectively deal with the competitive forces that determine success within an industry [9-11]. Porter $[1,2]$ identifies cost leadership as the ability to be the least cost producer in an industry for a given level of quality. Thus, a cost leadership strategy is intended to generate a competitive advantage by achieving costs that are lower than all competitors. Firms can adopt different resource allocation methods to achieve cost leadership: large scale facilities, process improvements, cost minimization, TQM, benchmarking, and overhead control [1, 2]. Hambrick [3] argues that cost leadership is achieved through efficiency which leads to lower prices. Efficiency can be obtained by cost efficiency (the cost per unit of output compared to competitors) and asset parsimony (assets per unit of output). Firms will improve their financial performance to the extent that they can succeed in deploying the minimum amount of assets and inputs to achieve the desired sales $[1,3,12]$. Cost efficiency and asset parsimony described above in essence refer to minimization of inputs for a given output, which is another way of defining efficiency maximization. Hence it becomes clear that a firm that pursues cost leadership will seek to maximize its production efficiency. Based on the above discussion, we state our first hypothesis as follows.

\section{H1: Firms pursuing a cost leadership strategy are associated with higher production efficiency.}

Firms adopting a differentiation strategy seek to create value through customer loyalty, price inelasticity, and unique image which they achieve via brand image, advertising intensity, novelty, fashion, and exclusive distribution networks $[13,14]$. Thus, these firms seek to achieve a competitive advantage by investing in developing products or services that offer unique qualities desirable to customers [10, 11]. Innovative and growth strategies which are associated with differentiation are more likely to yield results in the long run rather than in the short run and there is a greater chance of failure associated with these strategies compared to less innovative strategies [15]. The means to achieve a differentiation strategy do not easily lend themselves to production efficiency maximization. For example, the amount of inputs required to produce a Rolls-Royce car will be much greater than that required to produce a generic sedan. Hence the production efficiency of the Rolls producer will be much lower than that of the generic car producer. However, this lower production efficiency arises out of a deliberate strategy followed by Rolls-Royce which enables them to compete with other auto companies, although not on price. This implies that ceteris-paribus, firms that concentrate on differentiation ipso-facto, will have lower production efficiency. Stated formally,

H2: Firms that follow a differentiation strategy are associated with lower production efficiency.

\section{Empirical Estimation}

3.1. Measuring Production Efficiency Using Data Envelopment Analysis. We employ data envelopment analysis (DEA) to measure the production efficiency of the firms, which is an integral part of testing our hypotheses. DEA is a tool used to measure the production efficiency of decision making units. It is a nonparametric linear programming method that has become very popular in management science and economics to estimate production efficiency. Introduced by Charnes et al. [16] and extended by Banker et al. [17], DEA has become an important tool to estimate the relative production efficiency 
of business firms and other organizations. DEA does not specify the underlying production functional form in order to measure the production efficiency of a firm or a decision making unit. Hence DEA is a versatile tool that makes it suitable for many applications at the macrolevel as well as the microlevel. Banker et al. [18], Chen et al. [19], and Raab and Feroz [20] provide examples of macro- and microapplication of DEA). We use a two-stage DEA model using the DEA model of Banker et al. [17] (hereafter referred to as the BCC model) in the first stage of our empirical analysis and Tobit regressions in the second stage. The BCC model estimates the production efficiency scores of the firms in the Compustat database, and the second stage relates the production efficiency scores to our strategy variables. We follow Chang et al. [21] in our choice of input and output variables. We consider three inputs and one output in the DEA model. The three inputs are cost of goods sold (CoGS, Compustat Data 41), selling and distribution (SGA, Compustat Data 189), and capital expenditure (Cap Ex, Compustat Data 128) while the output is sales revenue (Compustat Data 12$)^{1}$. Prior studies have used Compustat financial data in DEA analyses to measure efficiency [22-26]. Thore et al. [27, page 229] state that "DEA is here employed to estimate the intertemporal productive efficiency of US computer manufacturers, using financial data from earnings statements and balance sheets." DEA measures the relative production efficiency relative to all other firms in the dataset. Therefore, we follow Chang et al. [21] and partition our main dataset into the different industry categories, using the Fama-French 12 industry classification ${ }^{2}$. This enables us to estimate DEA for each industry dataset separately and compute efficiency scores for each firm relative to similar firms in the same industry. Specifically, we estimate the production efficiency of firm $\Phi_{j}$ using the following linear program ${ }^{3}$ :

$$
\begin{aligned}
\Phi_{j}=\min & \Phi \\
\text { s.t. } & \Phi X_{j i} \geq \sum_{j=1}^{N} \lambda_{j} X_{j i}, \quad i=1,2,3 \\
& Y_{j} \leq \sum_{j=1}^{N} \lambda_{j} Y_{j} \\
& \sum_{j=1}^{N} \lambda_{j}=1 \\
& \lambda_{j} \geq 0,
\end{aligned}
$$

where $X_{j i}$ is level of input $i$ consumed by firm ${ }_{j}, Y_{j}$ is level of output produced by firm ${ }_{j}$, and $\lambda_{j}$ is weight placed on inputs/output of firm .

The linear program is solved for each observation $j$. The above models are constructed under the assumption of variable returns to scale and referred to as the BCC models of DEA [17]. If a constant return to scale is maintained instead, constraint (1c) is removed and the resulting model is labeled as the CCR model of DEA [16].

3.2. Strategic Positioning of Firms. Balsam et al. [28] survey the prior literature and capture the strategic positioning of the firms using realized indicators obtained through firms' financial statements. Following Balsam et al. [28], we use SG\&A/SALES, R\&D/SALES, and SALES/COGS to measure strategic positioning based on the differentiation dimension and use SALES/CAPEX, SALES/P\&E, and EMPL/ASSETS to measure strategic positioning based on cost leadership. A firm's long term strategy is revealed through these measures.

SG\&A/SALES is the ratio of the selling, general, and administrative expenses to net sales. This measure captures the firms efforts to differentiate itself from customers through marketing oriented activities such as brand development [2830]. R\&D/SALES is the ratio of the research and development expenses to net sales. R\&D expenditure indicates a firm's focus on high quality and innovative products/services that are essential for the success of differentiators. The firm's ability to provide such products and services is captured by its willingness to spend on innovation and product design $[3,28,30]$. SALES/COGS is the ratio of net sales to cost of goods sold. This variable captures the ability of differentiators to obtain higher profit margins through premium pricing $[29,31,32]$. SALES/CAPEX is the ratio of net sales to capital expenditures on property, plant, and equipment and SALES/P\&E is the ratio of net sales to net book value of plant and equipment. These two variables indicate efficient usage of a firm's resources, normally associated with cost leaders $[3,28,29,31]$. Finally, EMPL/ASSETS is the ratio of number of employees to total assets $[3,28,31]$ and also captures the firms efficiency in utilizing its resources. Accordingly, we use three measures to capture the differentiation strategy construct and three measures to capture the efficiency strategy construct. To capture the long term strategic orientation of firms we compute the mean, by firm, of the previous five years for each of the variables [28]. Next, we conduct a confirmatory factor analysis (CFA) to examine if the variables load on the expected strategy dimensions as suggested by the theoretical arguments. The results of the CFA, tabulated in Table 1 , provide support for the fit of the proposed measurement model. The factor loadings on the strategy variables for the two factors range from 0.51 to 0.96 with $t$-statistics for each of the factor loadings suggesting that the indicator measures satisfy convergent validity $[33,34]$.

Prior research $[35,36]$ prescribes a threshold of 0.7 for the composite reliability score, which measures the internal consistency of the factors. The two strategy factors used in this study comfortably exceed this threshold. The discriminant validity of these constructs is established by the average variance extracted (AVE). The AVE captures the amount of variance by an underlying factor (in this case, our constructs) in relation to the amount of variance due to measurement errors [28]. Fornell and Larcker [37] recommend a threshold of 5, and the AVE exceeds that threshold for all factors. We also examine several different indices to evaluate whether the measurement model provides a good fit. We use several other tests of validity and reliability. Joreskog and Sorbom [38] recommend a cut-off of 0.90 for the "goodness of fit" and 0.80 for the "adjusted goodness of fit index." Our measures are again comfortably above the threshold. Finally, our measures of the comparative fit index [39] and the nonnormed index [40] fall within the acceptable limits. 
TABLE 1: Factor analysis to confirm strategy constructs $(N=33,449)$.

\begin{tabular}{|c|c|c|c|c|}
\hline \multirow[b]{2}{*}{ Variables } & \multicolumn{4}{|c|}{ Confirmatory factor analysis } \\
\hline & $\begin{array}{c}\text { Cost leadership } \\
\text { factor loading } \\
(t \text {-value })\end{array}$ & $\begin{array}{c}\text { Differentiation } \\
\text { factor loading } \\
(t \text {-value })\end{array}$ & $\begin{array}{l}\text { Composite } \\
\text { reliability }\end{array}$ & $\begin{array}{l}\text { Average variance } \\
\text { extracted (AVE) }\end{array}$ \\
\hline SG\&A/SALES & & $0.96(150.60)$ & & \\
\hline $\mathrm{R} \& \mathrm{D} / \mathrm{SALES}$ & & $0.70(119.60)$ & & \\
\hline SALES/COGS & & $0.54(79.62)$ & 0.79 & 0.57 \\
\hline SALES/CAPEX & $0.86(171.70)$ & & & \\
\hline SALES/P\&E & $0.91(183.00)$ & & & \\
\hline EMPL/ASSETS & $0.51(99.36)$ & & 0.82 & 0.61 \\
\hline \multirow{4}{*}{ Goodness of fit measures } & \multicolumn{3}{|c|}{ Goodness of fit index } & 0.9584 \\
\hline & \multicolumn{3}{|c|}{ Goodness of fit index adjusted for degrees of freedom } & 0.8907 \\
\hline & \multicolumn{3}{|c|}{ Bentler's comparative fit index } & 0.9415 \\
\hline & \multicolumn{3}{|c|}{ Bentler \& Bonett's nonnormed index } & 0.8903 \\
\hline
\end{tabular}

SG\&A/SALES $=$ average of SG\&A/net sales from $t-1$ to $t-5$.

$\mathrm{R} \& \mathrm{D} / \mathrm{SALES}=$ average of R\&D Exp/net sales from $t-1$ to $t-5$.

SALES/COGS $=$ average of net sales/cost of goods sold from $t-1$ to $t-5$.

SALES/CAPEX $=$ average of net sales/Capital expenditure from $t-1$ to $t-5$.

SALES/P\&E $=$ average of net sales/net book value of plant and equipment from $t-1$ to $t-5$.

EMPL/ASSETS $=$ number of employees/average of total asset from $t-1$ to $t-5$.

The results reveal reasonable levels of reliability and validity for the measurement model, thus providing a sound basis for developing the two strategy scales based on the six firm-level measures. The two strategy scales are continuous variables and are orthogonal to each other. Thus, we operationalize a firm's realized strategy as a position on a Cartesian plane where the two axes represent the two generic strategies, cost leadership, and differentiation. A particular firm's strategic position is defined by that firm's factor scores in each of the two strategy scales.

3.3. Estimation Model. We use a two-stage method to evaluate our hypotheses on the impact of firm strategy on production efficiency. We estimate the second stage using two methods, OLS and Tobit regressions per Banker and Natarajan [41]. This two-stage approach is widely used in Accounting, Finance, Economics, and Operations management literature and has been validated by many studies such as Hoff [42] and McDonald [43]. Studies have used this approach to capture firm performance in specific industries such as banking (i.e., [44-47]), insurance (i.e., [48, 49]), telecommunication (i.e., [50]), and pharmaceutics (i.e., [51]). Studies [52] have also used this approach to capture the efficiency of universities. Further, this approach is widely used to evaluate the performance of firms in studies evaluating research questions beyond specific industries (see, e.g.): [21, $53,54])$. Following OLS regression model for the second stage estimation as used by Chang et al. [55], McDonald [43], and Cummins et al. [49] we estimate the following estimation model:

Production efficiency

$$
\begin{aligned}
= & \alpha_{0}+\alpha_{1} \mathrm{CL}+\alpha_{2} \text { Diff }+\alpha_{3} \text { Size }+\alpha_{4} \mathrm{ROA}+\alpha_{5} \text { Age } \\
& +\alpha_{6} \text { Competition }+ \text { Year } \& \text { Industry Dummies } \\
& +\varepsilon_{\mathrm{it}}
\end{aligned}
$$

where "Production efficiency" denotes the production efficiency of the firm and is obtained from the DEA model shown in (1a), (1b), (1c), (1d), and (1e). CL and Diff are the strategy constructs which capture the strategic positioning of the firms. They are continuous variables constructed based on the factor analysis as discussed in the earlier section. Based on our hypothesis, we expect the coefficient of CL $\left(\alpha_{1}\right)$ to be positive and significant and the coefficient of Diff $\left(\alpha_{2}\right)$ to be negative and significant. We avoid the potential problem of correlation between production efficiency and the contextual variables [56] by using different variables in each of the stages.

Since the production efficiency is a variable between 0 and 1, some prior studies use Tobit regressions in the second stage of a DEA analysis [42, 57-60]. The merits of both methods are debated in operational research literature (see $[42,43])$. We also estimate model (2) using Tobit regression as well to evaluate the robustness of our results to alternated methods of estimation.

Following Bulan et al. [61], we include Size, ROA, Age, and Competition as control variables in our regression. Larger firms will enjoy economies of scale, and so they are expected to be more efficient. As firms get older, they will accumulate knowledge and experience and work out the problems in their systems, people, and machinery. Hence their production efficiency will increase with age [61, 62]. As the level of competition within an industry segment increases, firms will have to constantly improve production efficiency by extracting more output from the same input to stay competitive. Extant literature documents industry structure and competition [63] as factors that have an impact on production efficiency. Research and development expenditure $[61,64]$ also has a significant impact on efficiency; however, $R \& D$ is extensively captured in our proxies for strategy. Hence we do not include R\&D in our regression model. 
TABLe 2: Descriptive statistics $(N=33,499)$.

\begin{tabular}{lccccc}
\hline Variable & Mean & Median & Std Dev & $\begin{array}{c}\text { 25th } \\
\text { percentile }\end{array}$ & $\begin{array}{c}75 \text { th } \\
\text { percentile }\end{array}$ \\
\hline $\begin{array}{l}\text { Production } \\
\text { efficiency }\end{array}$ & 0.5601 & 0.5913 & 0.2190 & 0.4313 & 0.7142 \\
Size & 5.5660 & 5.4381 & 1.8304 & 4.1967 & 6.7772 \\
ROA & 0.0116 & 0.0387 & 0.1438 & -0.0075 & 0.0784 \\
Age & 28.41 & 28.00 & 13.71 & 16.00 & 37.00 \\
Competition & 0.0010 & 0.0002 & 0.0040 & 0.0000 & 0.0006 \\
\hline
\end{tabular}

See the appendix for variable definitions.

We use the log of Assets as a proxy for firm size. ROA is return of assets computed as annual net income scaled by total assets. Age is the firm age computed by determining the year in which the firm first appeared in the COMPUSTAT database. Competition is computed as the sales of the firm in question as a percentage of the total sales of that firm's industry segment to control for the competitive pressure faced by the firm. Finally, industry dummies, based on the Fama-French 12 industry classification, are used as proxy for the industry structure.

\section{Empirical Results}

4.1. Data. We use publicly available data from the Compustat database for this study. Our dataset contains all firm-years that are available on the Compustat dataset for which the relevant variables have valid figures (nonmissing and not invalid observations). The dataset spans 1993 to 2006 and contains 33,499 firm-year observations.

4.2. Descriptive Statistics. Table 2 provides the descriptive statistics for the variables in our estimation model. The mean production efficiency of the firms in our sample is 0.5601 . Considering that our measure of production efficiency is computed using DEA and the maximum possible efficiency level is 1 , most firms are operating at well below their maximum possible level. The mean ROA is 0.0116 and the average firm is 28.41 years old.

4.3. Strategic Positioning and Production Efficiency. We evaluate our two hypotheses by estimating the regression model (2). The results of our estimation are tabulated in Table 3.

Panel A tabulates the results using only the cost leadership measure, Panel B tabulates the results using only the differentiation measure, and Panel $\mathrm{C}$ tabulates the results with both the differentiation and cost leadership measures. The results in Panel A show a significant and positive relationship between cost leadership (coefficient estimate is 0.0099; $p$ value $<0.0001$ ) and production efficiency, and Panel B show a significant and negative relationship between differentiation (coefficient estimate is $-0.0378 ; p$ value $<0.0001$ ) and production efficiency. Further, the results reported in Panel C remain unchanged when we include both the cost leadership and differentiation measures. The coefficient estimate for cost leadership (coefficient estimate is 0.0056 ; $p$ value is 0.0076 ) is positive and significant while the coefficient estimate for differentiation (coefficient estimate is -0.0368 ; $p$ value $<$ $0.0001)$ continues to be negative and significant. The results support our hypotheses that firms which adopt a cost leadership strategy are associated with higher production efficiency while firms which adopt a differentiation strategy which are focused, among other things, on achieving higher brand recognition and innovative products do so at the expense of production efficiency.

The coefficient estimates for the control variables, in each of the panels of Table 3, also have the expected signs. The coefficient estimates in Panel C, which include both the strategy measures, for Size (coefficient estimate is $0.0411 ; p$ value $<0.0001$ ), ROA (coefficient estimate is $0.1921 ; p$ value $<0.0001$ ), Age (coefficient estimate is 0.0006 ; $p$ value $<$ 0.0001 ), and Competition (coefficient estimate is 4.9418; $p$ value is 0.0026 ), are all positive and significantly associated with production efficiency. The adjusted $R^{2}$ is $76.97 \%$ (in Panel C) indicating that our model captures most of the variation in production efficiency. The coefficients for the control variables in Panels A and B are consistent with what was reported for Panel C. We correct for autocorrelation and heteroscedasticity using the "clustering" method proposed by Petersen [65]. We compute the variance inflation factors (VIF) to check for multicollinearity; the VIF factors for all the variables in each of our equations are under 10, indicating that multicollinearity was not a problem.

Next, we estimate model (2) using Tobit regressions. The results are shown in Table 4.

The results of Table 4 confirm those of Table 3 and show that the findings are independent of the methodology used in the second stage of the DEA analysis. Panel A shows a positive and significant relationship between "cost leadership" and "production efficiency" and Panel B shows a negative and significant relationship between "differentiation" and production efficiency. Panel $\mathrm{C}$ displays the results of when both differentiation and cost leadership are included at the same time in the Tobit regression. Confirming the results of Panels $\mathrm{A}$ and $\mathrm{B}$ and also those of Table 3, Panel C shows that "cost leadership" is positive and significant and "differentiation" is negative and significant when both variables are included in the regression model together.

Our results indicate that the cost leadership strategy is associated with higher production efficiency. We conduct additional analysis to examine whether the link between production efficiency and cost leadership exists in the entire spectrum of the cost leadership variable. Specifically, we evaluate whether our results hold for the entire sample or are driven by certain subsets of it by creating pairs of subsamples of our data based on the cost leadership variable to evaluate whether the positive link between the two variables exists in every subsample. Each subsample pair is created by dividing the original sample into the top $X$ th percentile and the bottom $X$ th percentile of cost leadership where $X=\{10,25,33,50\}$. Table 5 shows the results of running regression model (2) (excluding the differentiation variable) for a representative selection of this set (i.e., the 33rd percentile).

Panels A and B show that cost leadership is positive and statistically significant for both the top 33rd percentile 
TABLE 3: Strategic positioning and production efficiency $(N=33,499)$. OLS regressions in the 2nd stage of 2-stage DEA analysis. Dependent variable: production efficiency.

\begin{tabular}{|c|c|c|c|c|c|c|c|c|c|}
\hline & \multicolumn{3}{|c|}{ Panel A } & \multicolumn{3}{|c|}{ Panel B } & \multicolumn{3}{|c|}{ Panel C } \\
\hline & Coefficient estimate & $t$-stat & $p$ value & Coefficient estimate & $t$-stat & $p$ value & Coefficient estimate & $t$-stat & $p$ value \\
\hline Intercept & -0.0106 & -1.26 & 0.2095 & -0.0114 & -1.37 & 0.1704 & -0.0121 & -1.46 & 0.1442 \\
\hline $\mathrm{CL}$ & 0.0099 & 4.71 & 0.0000 & & & & 0.0056 & 2.67 & 0.0076 \\
\hline Diff & & & & -0.0378 & -10.30 & 0.0000 & -0.0368 & -10.10 & 0.0000 \\
\hline Size & 0.0408 & 27.32 & 0.0000 & 0.0405 & 28.29 & 0.0000 & 0.0411 & 28.08 & 0.0000 \\
\hline ROA & 0.1890 & 25.97 & 0.0000 & 0.1940 & 27.07 & 0.0000 & 0.1921 & 26.78 & 0.0000 \\
\hline Age & 0.0008 & 6.44 & 0.0000 & 0.0006 & 5.32 & 0.0000 & 0.0006 & 5.02 & 0.0000 \\
\hline \multirow[t]{3}{*}{ Competition } & 5.1546 & 3.05 & 0.0023 & 5.0460 & 3.03 & 0.0025 & 4.9718 & 3.02 & 0.0026 \\
\hline & \multicolumn{3}{|c|}{ Industry dummies included } & \multicolumn{3}{|c|}{ Industry dummies included } & \multicolumn{3}{|c|}{ Industry dummies included } \\
\hline & \multicolumn{3}{|c|}{ Year dummies included } & \multicolumn{3}{|c|}{ Year dummies included } & \multicolumn{3}{|c|}{ Year dummies included } \\
\hline Adjusted $R^{2}$ & \multicolumn{3}{|c|}{0.7594} & \multicolumn{3}{|c|}{0.7693} & \multicolumn{3}{|c|}{0.7697} \\
\hline Total Obs & \multicolumn{3}{|c|}{33499} & \multicolumn{3}{|c|}{33499} & \multicolumn{3}{|c|}{33499} \\
\hline
\end{tabular}

See the appendix for variable definitions.

TABLE 4: Strategic positioning and production efficiency $(N=33,499)$. Tobit regressions in the 2 nd stage of 2-stage DEA analysis. Dependent variable: production efficiency.

\begin{tabular}{|c|c|c|c|c|c|c|c|c|c|}
\hline & \multicolumn{3}{|c|}{ Panel A } & \multicolumn{3}{|c|}{ Panel B } & \multicolumn{3}{|c|}{ Panel C } \\
\hline & Coefficient estimate & $t$-stat & $p$ value & Coefficient estimate & $t$-stat & $p$ value & Coefficient estimate & $t$-stat & $p$ value \\
\hline Intercept & -0.0112 & -3.04 & 0.0024 & -0.012 & -3.33 & 0.0009 & -0.0128 & -3.53 & 0.0004 \\
\hline $\mathrm{CL}$ & 0.00987 & 12.8 & $<0.0001$ & & & & 0.00556 & 7.29 & $<0.0001$ \\
\hline Diff & & & & -0.0377 & -40.1 & $<0.0001$ & -0.0367 & -38.63 & $<0.0001$ \\
\hline Size & 0.04102 & 109.4 & $<0.0001$ & 0.04063 & 113.83 & $<0.0001$ & 0.04126 & 112.46 & $<0.0001$ \\
\hline ROA & 0.18929 & 44.26 & $<0.0001$ & 0.1943 & 46.48 & $<0.0001$ & 0.19236 & 45.97 & $<0.0001$ \\
\hline Age & 0.00076 & 16.47 & $<0.0001$ & 0.00061 & 13.6 & $<0.0001$ & 0.00058 & 12.82 & $<0.0001$ \\
\hline \multirow[t]{3}{*}{ Competition } & 5.15574 & 32.89 & $<0.0001$ & 5.04723 & 32.94 & $<0.0001$ & 4.97243 & 32.41 & $<0.0001$ \\
\hline & \multicolumn{3}{|c|}{ Industry dummies included } & \multicolumn{3}{|c|}{ Industry dummies included } & \multicolumn{3}{|c|}{ Industry dummies included } \\
\hline & \multicolumn{3}{|c|}{ Year dummies included } & \multicolumn{3}{|c|}{ Year dummies included } & \multicolumn{3}{|c|}{ Year dummies included } \\
\hline Log likelihood & \multicolumn{3}{|c|}{27461} & \multicolumn{3}{|c|}{26758} & \multicolumn{3}{|c|}{27487} \\
\hline Total Obs & \multicolumn{3}{|c|}{33499} & \multicolumn{3}{|c|}{33499} & \multicolumn{3}{|c|}{33499} \\
\hline
\end{tabular}

See the appendix for variable definitions.

subsample and the bottom 33rd percentile subsample. The coefficient of the top 33rd subsample is larger than the bottom 33rd subsample, indicating that the impact of cost leadership is greater for the subsample where cost leadership is higher. These results hold for the 10th, 25th, and 50th percentile subsamples as well. Furthermore, untabulated results show that a replication of the analyses comparing the top and bottom 50th, 33rd, 25th, and 10th percentiles using a Tobit regression yields the same results.

Next, we formally evaluate whether $\alpha_{1}$ (the coefficient of cost leadership) of the top $X$ th subsample ( $\alpha_{1 T}$ hereafter) is significantly larger than $\alpha_{1}$ of the bottom $X$ th subsample $\left(\alpha_{1 B}\right.$ hereafter). If indeed there is a linear relationship between production efficiency and cost leadership, we expect $\alpha_{1 T}$ to be greater than $\alpha_{1 B}$ for all values of $X$. We develop a procedure based on bootstrapping [66] to test the difference in coefficients of the two subsamples ${ }^{4}$. The results are shown in Table 6.

The results in Table 6, Panels A through D, show that the difference is significant for each of the subsamples. Moreover, the difference increases as the difference of the cost leadership attribute between the two subsamples increases. The greatest difference is when the top 10th percentile is compared with the bottom 10th percentile. Thus, our additional analysis indicates that firms at the higher percentile of cost leadership are associated with higher levels of production efficiency.

To summarize, the results in Tables 3, 4, and 5 together support our hypotheses that the cost leadership strategy is associated with higher production efficiency while it is not as important for firms pursuing a differentiation strategy. The results in Tables 5 and 6 indicate that the positive (and statistically significant) relationship between production efficiency and cost leadership exists throughout the cost leadership spectrum; however, the relationship is greater at higher levels of cost leadership.

4.4. Sensitivity Analysis. We use an input-minimization DEA model since it is more appropriate for investigating the production efficiency of cost leadership firms. However, as a sensitivity measure, we also compute "production efficiency 
TABLE 5: Cost leadership strategy and production efficiency. Low cost leadership firms compared to high cost leadership firms. Dependent variable: production efficiency.

\begin{tabular}{|c|c|c|c|c|c|c|}
\hline & \multicolumn{3}{|c|}{ Panel A: High cost leadership (top 33\%) } & \multicolumn{3}{|c|}{ Panel B: Low cost leadership (bottom 33\%) } \\
\hline & Coefficient estimate & $t$-stat & $p$ value & Coefficient estimate & $t$-stat & $p$ value \\
\hline Intercept & -0.0829 & -3.94 & 0.0000 & -0.0119 & -0.83 & 0.4041 \\
\hline $\mathrm{CL}$ & 0.1110 & 3.83 & 0.0001 & 0.0077 & 3.09 & 0.0020 \\
\hline Size & 0.0454 & 27.45 & 0.0000 & 0.0465 & 23.47 & 0.0000 \\
\hline ROA & 0.0879 & 7.87 & 0.0000 & 0.2475 & 17.54 & 0.0000 \\
\hline Age & 0.0005 & 2.87 & 0.0042 & 0.0005 & 2.21 & 0.0269 \\
\hline \multirow[t]{3}{*}{ Competition } & 1.2515 & 2.50 & 0.0126 & 12.5400 & 7.54 & 0.0000 \\
\hline & \multicolumn{3}{|c|}{ Industry dummies included } & \multicolumn{3}{|c|}{ Industry dummies included } \\
\hline & \multicolumn{3}{|c|}{ Year dummies included } & \multicolumn{3}{|c|}{ Year dummies included } \\
\hline Adjusted $R^{2}$ & \multicolumn{3}{|c|}{0.8151} & \multicolumn{3}{|c|}{0.7287} \\
\hline Total Obs & \multicolumn{3}{|c|}{11074} & \multicolumn{3}{|c|}{11101} \\
\hline
\end{tabular}

See the appendix for variable definitions.

TABLE 6: Bootstrap results of significance of the difference in the CL coefficient between high and low cost leadership samples.

\begin{tabular}{|c|c|c|c|c|c|c|}
\hline & Coefficient estimate & $t$-stat & $p$ value & Coefficient estimate & $t$-stat & $p$ value \\
\hline \multicolumn{7}{|c|}{ Panel A: Top 50th percentile versus bottom 50th percentile } \\
\hline CL & 0.0999 & 406.88 & 0.0000 & 0.0064 & 154.24 & 0.0000 \\
\hline Difference & 0.0935 & 375.38 & 0.0000 & & & \\
\hline \multicolumn{7}{|c|}{ Panel B: Top 33rd percentile versus bottom 33rd percentile } \\
\hline $\mathrm{CL}$ & 0.1167 & 265.55 & 0.0000 & 0.0062 & 132.76 & 0.0000 \\
\hline Difference & 0.1104 & 249.97 & 0.0000 & & & \\
\hline \multicolumn{7}{|c|}{ Panel C: Top 25th percentile versus bottom 25th percentile } \\
\hline $\mathrm{CL}$ & 0.1294 & 214.16 & 0.0000 & 0.0063 & 125.70 & 0.0000 \\
\hline Difference & 0.1231 & 202.97 & 0.0000 & & & \\
\hline \multicolumn{7}{|c|}{ Panel D: Top 10th percentile versus bottom 10th percentile } \\
\hline $\mathrm{CL}$ & 0.3183 & 186.75 & 0.0000 & 0.0100 & 144.808 & 0.0000 \\
\hline Difference & 0.3083 & 180.75 & 0.0000 & & & \\
\hline
\end{tabular}

See the appendix for variable definitions.

scores" using an output maximization DEA model. Our results do not change qualitatively and are therefore robust to different specifications of the DEA model.

\section{Conclusion}

This paper presents a unique application of DEA in examining the importance of production efficiency in the context of strategic positioning of firms, thus providing insights into an aspect of evaluating the effectiveness of firms in achieving their strategic positioning. The importance of clearly defined strategy for long term success of firms is well documented $[1,3]$. Similarly, effective implementation of the strategy is equally important for long term success [4]. Firms pursuing either a cost leadership or a differentiation strategy stand to achieve superior contemporaneous performance. Specifically, firms pursuing a cost leadership strategy seek to be the lowest cost producer, primarily by minimizing inputs for a given level of output, thereby improving production efficiency. While firms which pursue a differentiation strategy seek to achieve a competitive edge primarily through creating superior products, packaging and branding, these firms create a unique image in the minds of their consumers. Such firms do not put much importance on production efficiency. We posit that firms pursuing cost leadership strategy put high importance on production efficiency while production efficiency is not as important to firms pursuing a differentiation strategy.

We examine this contention using publicly available data. We compute proxies for a firm's strategic positioning using Balsam et al. [28]. We compute firms' production efficiency measures using Banker et al. [17] and then test our hypotheses using the two-stage DEA analysis. Our analysis indicates that firms which pursue a cost leadership strategy are strongly and positively associated with higher production efficiency, while firms pursuing a differentiation strategy are negatively associated with production efficiency possibly due to the fact that these differentiators typically focus more on product and service aspects rather than production efficiency. Further, our additional analysis using the bootstrapping procedure 
indicates that higher degree of cost leadership is positively associated with production efficiency through the entire spectrum of the cost leadership proxy.

When evaluating our results, it is important to keep in mind the criticisms of the 2-stage approach to evaluating production efficiency by Simar and Wilson [67]. However, even after this paper was published, many articles that use the 2-stage DEA approach have appeared in leading journals $[48,50,52-54]$. Therefore, the results of our study have to be evaluated in the context of both the Simar and Wilson [67] criticism of the 2-stage model and its continuing popularity in operations research.

Our paper makes several important contributions to the literature. First, we document the association between firm strategy, specifically the cost leadership strategy and production efficiency. Second, we highlight how estimated production efficiency can be used to evaluate one important aspect of a cost leadership strategy. One facet of a cost leadership strategy can be implemented ex ante by concentrating on production efficiency improvement; moreover, the effectiveness of strategy implementation can be evaluated ex post by comparing production efficiency of a cost leadership firm against the production efficiency frontier for that industry ${ }^{5}$. Third, we highlight another area of business that lends itself to both academic and practical applications of DEA.

Our results are important to strategy formulators, managers, financial analysts, and investors alike. For the former group, our study provides additional insights on cost leadership and differentiation strategies and on ways in which such strategies can be implemented and how such implementation can be evaluated. To the latter group our study provides a means of ex-post evaluating the implementation effectiveness of a firm's stated strategy.

Our study points to several avenues for future research. One such research would be to investigate the continuing role that production efficiency plays in firm strategy, as the discipline of strategy itself evolves beyond the "generic strategy" paradigm of Porter [1]. Furthermore, future research could evaluate our findings in an international context and explore whether cost leaders universally pursue production efficiency improvements to achieve low costs.

\section{Appendix}

\section{Variables Used in Computing the DEA Score}

Inputs

Cost of goods sold (COGS, Compustat Data 41).

Selling and distribution (SGA, Compustat Data 189).

Capital expenditure (Cap Ex, Compustat Data 128).

Output

Sales revenue (Compustat Data 12).

Variables Used in the Second Stage of the Regression

Production efficiency: Production efficiency of the firm (measured using DEA).
CL: Construct to capture cost leadership. Continuous variable, based on the factor analysis of the $t-1$ to $t-5$ average of the ratios of sales to capital expenditure, sales to net book value of plant and equipment, and number of employees to net book value of plant and equipment.

Diff: Construct to capture differentiation. Continuous variable based on the factor analysis of the $t-1$ to $t-5$ average of the ratios of SG\&A Exp to sales, R\&D expense to sales, and sales to cost of goods sold.

Size: Natural log of assets (Compustat data \#6).

ROA: Return on assets (Net income (Compustat data \#18)/total assets (Compustat data \#6)).

Age: Current year minus the year in which the firm first appeared in Compustat.

Competition: Sales of the firm scaled by the sales of all of the firms in the same industry category.

\section{Conflict of Interests}

The authors declare that there is no conflict of interests regarding the publication of this paper.

\section{Endnotes}

1. Please see the appendix for definitions of these input and output variables.

2. Prior studies [68-71] have used this classification and found it as a reasonably homogenous industry grouping.

3. We estimate production efficiency assuming Hicksian neutral technical change and follow the procedure specified in Chang et al. [21].

4. The bootstrapping procedure we use is as follows. Consider the top $X$ th $($ sample size $=11,074)$ and bottom $X$ th ( sample size $=11,101)$ associated with the 33rd percentile. We draw random subsamples (with replacement) from the top $X$ th sample so that we get a sample which has the same number of observations as the top $X$ th. We do this a thousand times. We estimate model 2 and obtain the coefficient of "cost leadership" (i.e., $\alpha_{1}$ ) for each of these one thousand samples. Next we obtain the mean of the one thousand coefficients for $\alpha_{1}$ for the top $X$ th sample $\left(\alpha_{1 T}\right)$. We repeat the procedure for the bottom $X$ th sample and obtain $\alpha_{1 B}$. Since the theory behind bootstrapping indicates that $\alpha_{1 T}$ and $\alpha_{1 B}$ have random normal distributions, we use the difference of means test to find out if the difference between the two is significant. We repeat the same procedure for cutoffs of $50 \%, 25 \%$, and $10 \%$.

5. High productive efficiency is a sine qua non for a successful cost leadership strategy. DEA enables us to determine the production efficiency frontier for each industry. Therefore, a firm which has implemented a cost leadership strategy could evaluate the success of its strategy implementation by evaluating how close 
its post implementation production efficiency is to the efficiency frontier of its industry category. However, it must be noted that a high production efficiency by itself does not indicate a totally successful cost leadership strategy implementation; other aspects of a successful implementation would be as capturing market share, judicious selection of product line-up access to low cost raw materials, and so forth.

\section{References}

[1] M. Porter, Competitive Strategy: Techniques for Analyzing Industries and Competitors, Free Press, New York, NY, USA, 1980.

[2] M. Porter, Competitive Advantage, Free Press, New York, NY, USA, 1985.

[3] D. C. Hambrick, "Some tests of the effectiveness and functional attributes of Miles and Snow's strategic types," Academy of Management Journal, vol. 26, no. 1, pp. 5-26, 1983.

[4] M. Porter, "What is strategy?" Harvard Business Review, pp. 5979, 1996.

[5] P. Calthrop, The Six Disciplines of Cost Leadership on CEOFORUMGROUP, 2010, http://www.ceoforum.com.au/articledetail.cfm?cid=6275\&t=/Paul-Calthrop-Bain-International/Thesix-disciplines-of-cost-leadership.

[6] H. O. Fried, C. A. K. Lovell, and S. S. Schmidt, Eds., The Measurement of Productive Efficiency, Oxford University Press, New York, NY, USA, 1993.

[7] T. J. Coelli, D. S. P. Rao, C. J. O’Donnell, and G. E. Battese, An Introduction to Efficiency and Productivity Analysis, Springer, New York, NY, USA, 2005.

[8] R. Färe, S. Grosskopf, and C. A. K. Lovell, The Measurement of Efficiency of Production, Kluwer-Nijhoff, Boston, Mass, USA, 1985.

[9] K. Amoako-Gyampah and M. Acquaah, "Manufacturing strategy, competitive strategy and firm performance: an empirical study in a developing economy environment," International Journal of Production Economics, vol. 111, no. 2, pp. 575-592, 2008.

[10] S. Cai, X. Chen, and I. Bose, "Exploring the role of IT for environmental sustainability in China: an empirical analysis," International Journal of Production Economics, vol. 146, no. 2, pp. 491-500, 2013.

[11] S. Cai and Z. Yang, "On the relationship between business environment and competitive priorities: the role of performance frontiers," International Journal of Production Economics, vol. 151, pp. 131-145, 2014.

[12] D. Miller, "The structural and environmental correlates of business strategy," Strategic Management Journal, vol. 8, no. 1, pp. 55-76, 1987.

[13] R. S. Chaganti, R. Chaganti, and V. Mahajan, "Profitable strategies under different types of competition," EntrepreneurshipTheory and Practice, vol. 13, pp. 21-35, 1989.

[14] J. B. Mason, M. L. Mayer, and H. F. Ezell, Retailing, Irwin, Homewood, Ill, USA, 2nd edition, 1991.

[15] C. S. Galbraith and G. B. Merrill, "The effect of compensation program and structure on sbu competitive strategy: a study of technology-intensive firms," Strategic Management Journal, vol. 12, no. 5, pp. 353-370, 1991.
[16] A. Charnes, W. W. Cooper, and E. Rhodes, "Measuring the efficiency of decision making units," European Journal of Operational Research, vol. 2, no. 6, pp. 429-444, 1978.

[17] R. D. Banker, A. Charnes, and W. W. Cooper, "Some models for the estimating technical and scale inefficiencies in data envelopment analysis," Management Science, vol. 30, no. 9, pp. 1078-1092, 1984.

[18] R. D. Banker, H. Chang, and R. Natarajan, "Productivity change, technical progress, and relative efficiency change in the public accounting industry," Management Science, vol. 51, no. 2, pp. 291-304, 2005.

[19] A. Chen, Y. Hwang, and B. Shao, "Measurement and sources of overall and input inefficiencies: evidences and implications in hospital services," European Journal of Operational Research, vol. 161, no. 2, pp. 447-468, 2005.

[20] R. L. Raab and E. H. Feroz, "A productivity growth accounting approach to the ranking of developing and developed nations," The International Journal of Accounting, vol. 42, no. 4, pp. 396415, 2007.

[21] H. Chang, G. D. Fernando, D. Srinivasan, and A. Tripathy, "A re-examination of diversification and firm productivity," Journal of Management Accounting Research, vol. 25, no. 1, pp. 99-118, 2013.

[22] H.-C. Tsai, C.-M. Chen, and G.-H. Tzeng, "The comparative productivity efficiency for global telecoms," International Journal of Production Economics, vol. 103, no. 2, pp. 509-526, 2006.

[23] C. Lin, Y. Ma, and D. Su, "Corporate governance and firm efficiency: evidence from China's publicly listed firms," Managerial and Decision Economics, vol. 30, no. 3, pp. 193-209, 2009.

[24] V. Zelenyuk and V. Zheka, "Corporate governance and firm's efficiency: the case of a transitional country, Ukraine," Journal of Productivity Analysis, vol. 25, no. 1, pp. 143-157, 2006.

[25] K. Cullinane, D.-W. Song, and T. Wang, "The application of mathematical programming approaches to estimating container port production efficiency," Journal of Productivity Analysis, vol. 24, no. 1, pp. 73-92, 2005.

[26] M. U. Ahmed, M. K. Mehmet, and M. Pagell, "Impact of operational and marketing capabilities on firm performance: evidence from economic growth and downturns," International Journal of Production Economics, vol. 154, pp. 59-71, 2014.

[27] S. Thore, G. Kozmetsky, and F. Phillips, "DEA of financial statements data: the U.S. computer industry," Journal of Productivity Analysis, vol. 5, no. 3, pp. 229-248, 1994.

[28] S. Balsam, G. D. Fernando, and A. Tripathy, "The impact of firm strategy on performance measures used in executive compensation," Journal of Business Research, vol. 64, no. 2, pp. 187-193, 2011.

[29] S. L. Berman, A. C. Wicks, S. Kotha, and T. M. Jones, "Does stakeholder orientation matter? The relationship between stakeholder management models and firm financial performance," Academy of Management Journal, vol. 42, no. 5, pp. 488-506, 1999.

[30] J. S. David, Y. Hwang, B. K. W. Pei, and J. H. Reneau, “The performance effects of congruence between product competitive strategies and purchasing management design," Management Science, vol. 48, no. 7, pp. 866-885, 2002.

[31] S. Kotha and A. Nair, "Strategy and environment as determinants of performance: evidence from the Japanese machine tool industry," Strategic Management Journal, vol. 16, no. 7, pp. 497518, 1995. 
[32] A. Nair and L. Filer, "Cointegration of firm strategies within groups: a long-run analysis of firm behavior in the Japanese steel industry," Strategic Management Journal, vol. 24, no. 2, pp. 145159, 2003.

[33] R. P. Bagozzi, Y. Yi, and L. W. Phillips, "Assessing construct validity in organizational research," Administrative Science Quarterly, vol. 36, no. 3, pp. 421-458, 1991.

[34] L. W. Phillips, "Assessing measurement error in key informant reports: a methodological note on organizational analysis in marketing," Journal of Marketing Research, vol. 18, no. 4, pp. 395-415, 1981.

[35] C. Werts, R. Linn, and K. Joreskog, "Interclass reliability estimates: testing structural assumptions," Educational and Psychological Measurement, vol. 34, pp. 25-33, 1974.

[36] J. C. Nunnally, Psychometric Theory, McGraw-Hill, New York, NY, USA, 2nd edition, 1978.

[37] C. Fornell and D. F. Larcker, "Evaluating structural equation models with unobservable variables and measurement errors," Journal of Marketing Research, vol. 18, no. 1, pp. 39-50, 1981.

[38] K. G. Joreskog and D. Sorbom, LISREL 7: A Guide to Program and Applications, SPSS, Chicago, Ill, USA, 2nd edition, 1989.

[39] P. M. Bentler, EQS Structural Equations Program Manual, BMDP Software, Los Angeles, Calif, USA, 1989.

[40] P. M. Bentler and D. G. Bonett, "Significance tests and goodness of fit in the analysis of covariance structures," Psychological Bulletin, vol. 88, no. 3, pp. 588-606, 1980.

[41] R. D. Banker and R. Natarajan, "Evaluating contextual variables affecting productivity using DEA," Operations Research, vol. 56, no. 1, pp. 48-58, 2008.

[42] A. Hoff, "Second stage DEA: comparison of approaches for modelling the DEA score," European Journal of Operational Research, vol. 181, no. 1, pp. 425-435, 2007.

[43] J. McDonald, "Using least squares and tobit in second stage DEA efficiency analyses," European Journal of Operational Research, vol. 197, no. 2, pp. 792-798, 2009.

[44] P. Wanke, C. P. Barros, and J. R. Faria, "Financial distress drivers in Brazilian banks: a dynamic slacks approach," European Journal of Operational Research, vol. 240, no. 1, pp. 258-268, 2015.

[45] J. R. Barth, C. Lin, Y. Ma, J. Seade, and F. M. Song, "Do bank regulation, supervision and monitoring enhance or impede bank efficiency?" Journal of Banking \& Finance, vol. 37, no. 8, pp. 2879-2892, 2013.

[46] H. C. Hsiao, H. Chang, A. M. Cianci, and L.-H. Huang, "First Financial Restructuring and operating efficiency: evidence from Taiwanese commercial banks," Journal of Banking and Finance, vol. 34, no. 7, pp. 1461-1471, 2010.

[47] F. Sufian and M. S. Habibullah, "Asian financial crisis and the evolution of Korean banks efficiency: a DEA approach," Global Economic Review, vol. 38, no. 4, pp. 335-369, 2009.

[48] F. Sun, X. Wei, and X. Huang, "CEO compensation and firm performance: evidence from the US property and liability insurance industry," Review of Accounting and Finance, vol. 12, no. 3, pp. 252-267, 2013.

[49] J. D. Cummins, M. A. Weiss, X. Xie, and H. Zi, "Economies of scope in financial services: a DEA efficiency analysis of the US insurance industry," Journal of Banking and Finance, vol. 34, no. 7, pp. 1525-1539, 2010.

[50] W.-K. Wang, W.-M. Lu, Q. L. Kweh, and H.-W. Lai, “Does corporate social responsibility influence the corporate performance of the U.S. telecommunications industry?” Telecommunications Policy, vol. 38, no. 7, pp. 580-591, 2014.

[51] H. Saranga and R. D. Banker, "Productivity and technical changes in the Indian pharmaceutical industry," Journal of the Operational Research Society, vol. 61, no. 12, pp. 1777-1788, 2010.

[52] R.-R. Duh, K.-T. Chen, R.-C. Lin, and L.-C. Kuo, "Do internal controls improve operating efficiency of universities?" Annals of Operations Research, vol. 221, no. 1, pp. 173-195, 2014.

[53] P. Demerjian, B. Lev, M. Lewis, and S. McVay, "Managerial ability and earnings quality," The Accounting Review, vol. 88, no. 2, pp. 463-498, 2013.

[54] P. Demerjian, B. Lev, and S. McVay, "Quantifying managerial ability: a new measure and validity tests," Management Science, vol. 58, no. 7, pp. 1229-1248, 2012.

[55] H. Chang, W. J. Chang, S. Das, and S. H. Li, "Health care regulation and the operating efficiency of hospitals: evidence from Taiwan," Journal of Accounting and Public Policy, vol. 23, no. 6, pp. 483-510, 2004.

[56] R. B. Staub, G. da Silva e Souza, and B. M. Tabak, "Evolution of bank efficiency in Brazil: a DEA approach," European Journal of Operational Research, vol. 202, no. 1, pp. 204-213, 2010.

[57] E. C. Wang and W. Huang, "Relative efficiency of R\&D activities: a cross-country study accounting for environmental factors in the DEA approach," Research Policy, vol. 36, no. 2, pp. 260-273, 2007.

[58] M. D. Delis and N. I. Papanikolaou, "Determinants of bank efficiency: evidence from a semi-parametric methodology," Managerial Finance, vol. 35, no. 3, pp. 260-275, 2009.

[59] H.-J. Tu and W.-C. Yen, "Measuring the operating efficiency of internet channels using the two-stage DEA approach," Asia Pacific Management Review, vol. 18, no. 3, pp. 257-274, 2013.

[60] K. Cheng, Z.-H. Lee, and H. Shomali, "Airline firm boundary and ticket distribution in electronic markets," International Journal of Production Economics, vol. 137, no. 1, pp. 137-144, 2012.

[61] L. Bulan, P. Sanyal, and Z. Yan, "A few bad apples: an analysis of CEO performance pay and firm productivity," Journal of Economics and Business, vol. 62, no. 4, pp. 273-306, 2010.

[62] J. C. Haltiwanger, J. I. Lane, and J. R. Spletzer, "Productivity differences across employers: the roles of employer size, age, and human capital," American Economic Review, vol. 89, no. 2, pp. 94-98, 1999.

[63] J. Tang and W. Wang, "Product market competition, skill shortages and productivity: evidence from Canadian manufacturing firms," Journal of Productivity Analysis, vol. 23, no. 3, pp. 317339, 2005.

[64] Z. Griliches, "Productivity, R\&D, and basic research at the firm level in the 1970's," American Economic Review, vol. 76, pp. 141$154,1986$.

[65] M. A. Petersen, "Estimating standard errors in finance panel data sets: comparing approaches," Review of Financial Studies, vol. 22, no. 1, pp. 435-480, 2009.

[66] W. H. Greene, Econometric Analysis, Prentice-Hall, Englewood Cliffs, NJ, USA, 4th edition, 2000.

[67] L. Simar and P. W. Wilson, "Estimation and inference in two-stage, semi-parametric models of production processes," Journal of Econometrics, vol. 136, no. 1, pp. 31-64, 2007.

[68] D. K. Denis, J. J. Mcconnell, A. V. Ovtchinnikov, and Y. Yu, "S\&P 500 index additions and earnings expectations," The Journal of Finance, vol. 58, no. 5, pp. 1821-1840, 2003. 
[69] U. Malmendier and G. Tate, "CEO overconfidence and corporate investment," Journal of Finance, vol. 60, no. 6, pp. 26612700, 2005.

[70] V. R. Eleswarapu and K. Venkataraman, "The impact of legal and political institutions on equity trading costs: a crosscountry analysis," Review of Financial Studies, vol. 19, no. 3, pp. 1081-1111, 2006.

[71] F. Pérez-González, "Inherited control and firm performance," The American Economic Review, vol. 96, no. 5, pp. 1559-1588, 2006. 


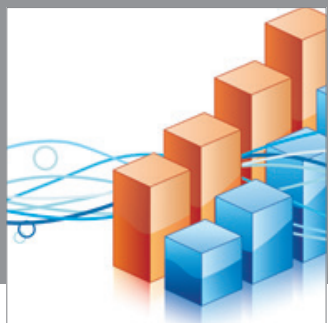

Advances in

Operations Research

mansans

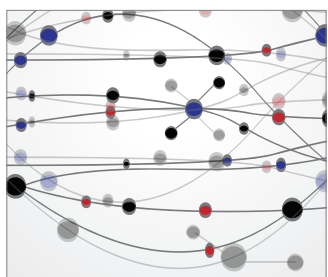

The Scientific World Journal
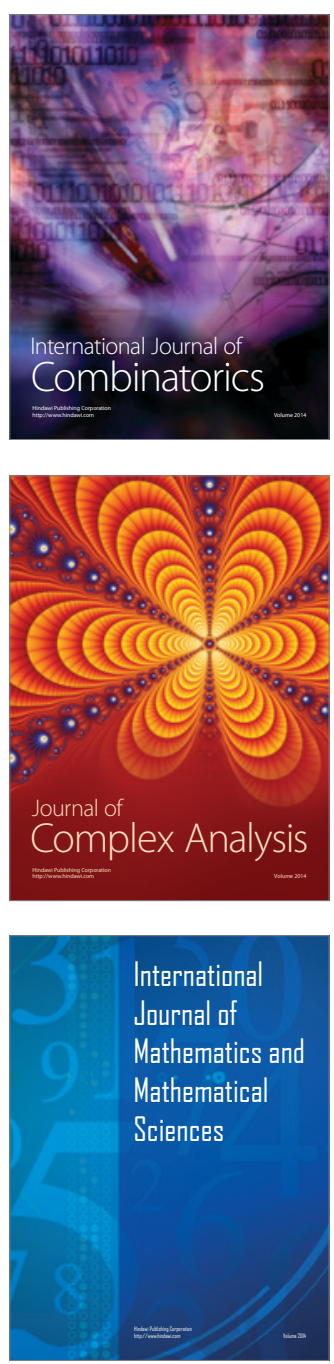
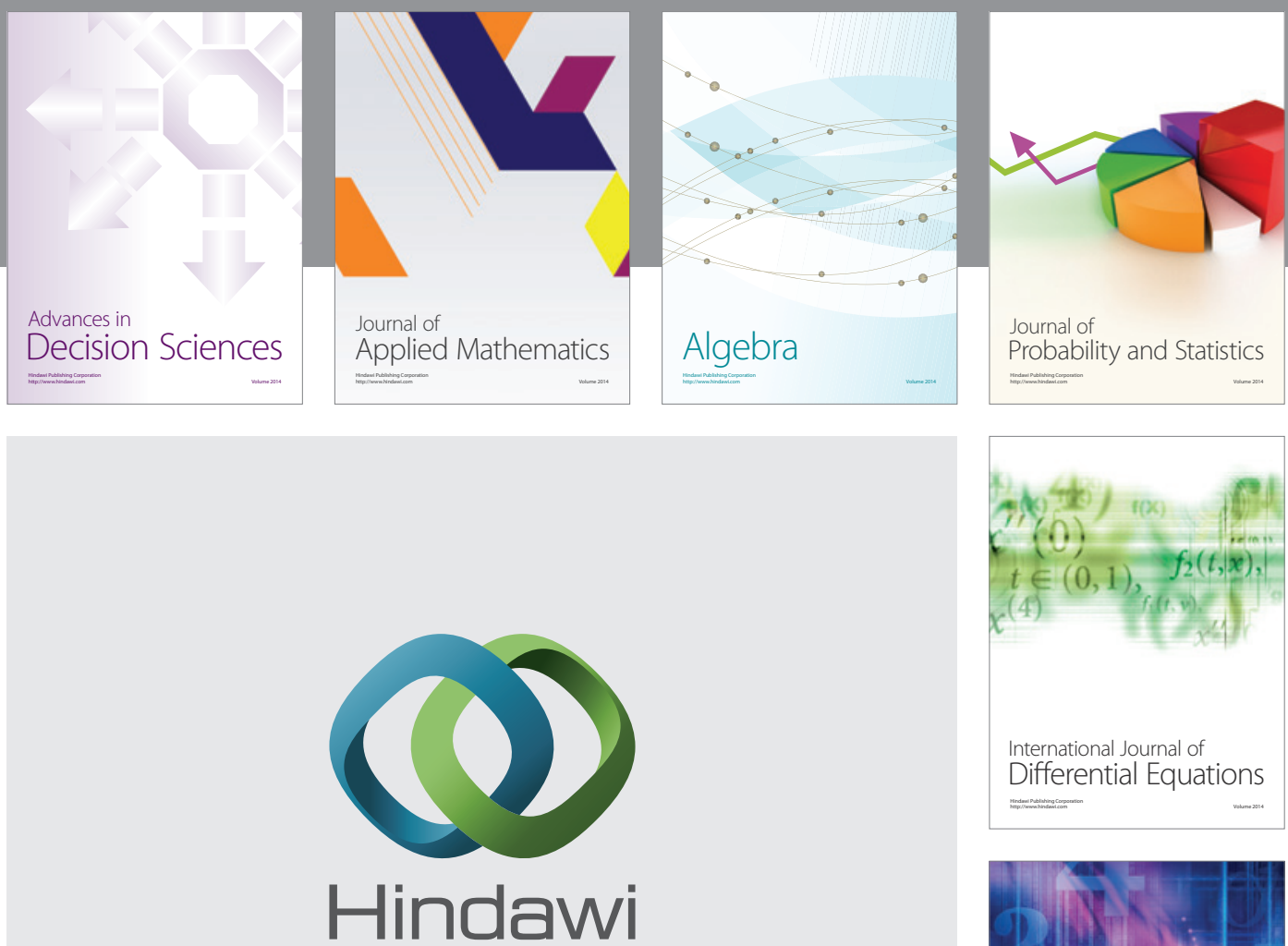

Submit your manuscripts at http://www.hindawi.com
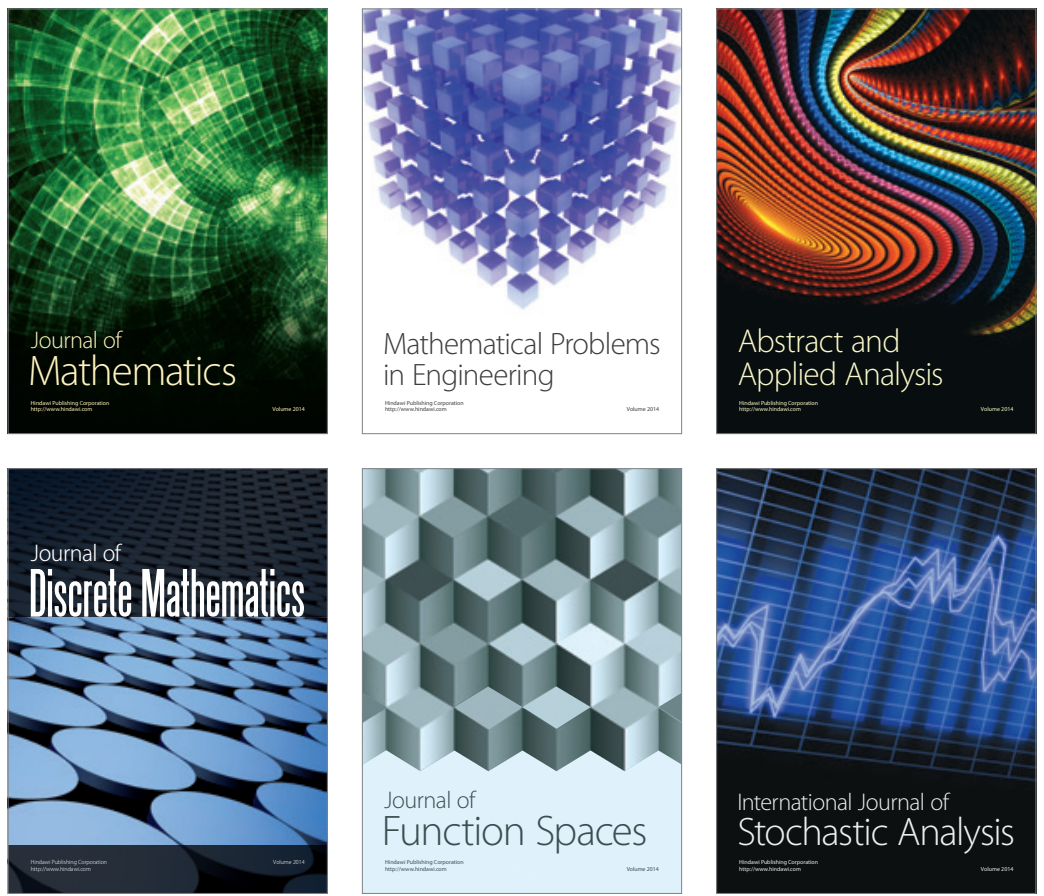

Journal of

Function Spaces

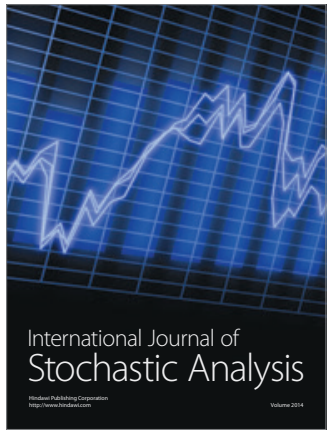

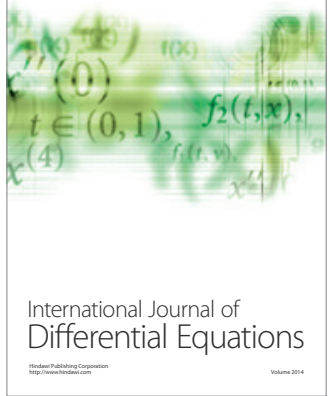
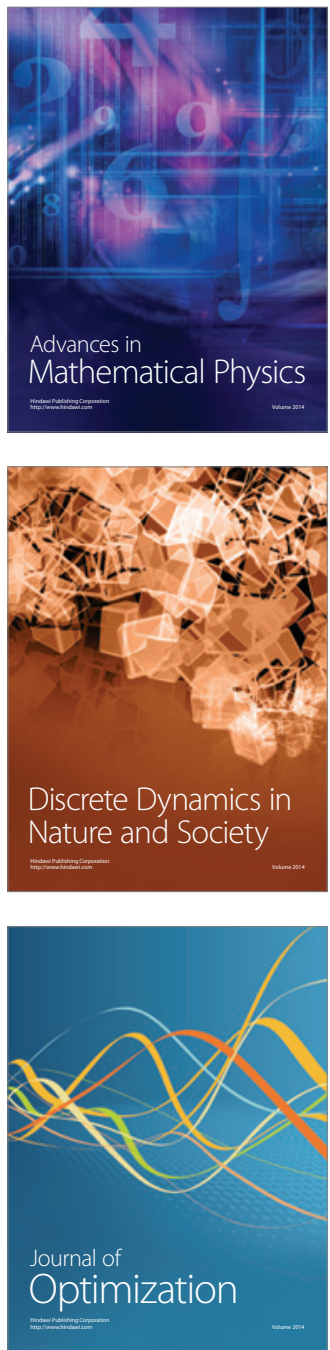